\title{
Synthesis of the $\mathrm{ZnGa}_{2} \mathrm{~S}_{4}$ Nanocrystals and Their Visible-Light Photocatalytic Degradation Property
}

\author{
Ding Peng, ${ }^{1}$ Zhang Min, ${ }^{1}$ Xie Zhonglei, ${ }^{2}$ and Cao Lihong ${ }^{3}$ \\ ${ }^{1}$ Department of Chemistry, Changchun Normal University, Changchun 130032, China \\ ${ }^{2}$ College of Environment and Resources, Jilin University, Changchun 130023, China \\ ${ }^{3}$ Northeast Coal Industry Environmental Research Ltd of Jilin, Changchun 130062, China \\ Correspondence should be addressed to Ding Peng; dingpb@163.com
}

Received 21 July 2014; Accepted 8 September 2014

Academic Editor: Weihang Zhou

Copyright (C) 2015 Ding Peng et al. This is an open access article distributed under the Creative Commons Attribution License, which permits unrestricted use, distribution, and reproduction in any medium, provided the original work is properly cited.

\begin{abstract}
Nanostructured $\mathrm{ZnGa}_{2} \mathrm{~S}_{4}$ with indirect band gap was prepared by a simple thiourea reduction method. As-prepared samples were characterized by X-ray diffraction (XRD), high resolution transmission electron microscopy (HRTEM), energy-dispersive X-ray spectroscopy (EDX), and UV-Vis diffuse reflectance spectra (UV-Vis). The visible-light photocatalytic activity of the $\mathrm{ZnGa}_{2} \mathrm{~S}_{4}$ was evaluated by the degradation of methylene blue $(\mathrm{MB})$ aqueous solution. The high photoactivities of $\mathrm{ZnGa}_{2} \mathrm{~S}_{4}$ can be attributed to the small band gap and large surface area, which is beneficial for degradation of pollutants and enhancement of transfer of photogenerated carriers.
\end{abstract}

\section{Introduction}

One of the major sources of water contamination is the dyeing and printing dye wastewater from various textile industries $[1,2]$. The dye wastewater contains high levels of organic pollutants, color rendering and alkaline $[3,4]$. In the past few decades, photocatalytic degradation is considered to be a feasible method to remove dyes from wastewater. Compared with the traditional processing methods, it can effectively and thoroughly destroy much structural stability of nonbiodegradable pollutants $[5,6]$. The semiconductor oxide usually can be used as photocatalyst, which is due to its special electronic structure, that is, a filled valence band and an empty conduction band [7-10]. However, these semiconductor oxide catalysts are usually synthesized at high temperature, and they only have ultraviolet photocatalytic activity. For the solar spectrum, only a small portion of solar energy (about 4\%) lies in the UV region, and visible solar spectrum represents a greater percentage (about 46\%) [11]. Recently, in the development of new catalysts in the field of visible light with rapid progress, these photocatalysts have proper band gap which can be used to drive a photocatalytic reaction and thus are suitable for sewage treatment and manufacturing of hydrogen energy [12, 13]. A large amount of nanostructured materials can be used for the photocatalytic degradation, due to their inherent properties, such as increasing photon absorption, improving charge transfer rate, high carrier separation, and surface reactivity, arising from their large specific surface area $[14,15]$.

Recently, the semiconductor oxides of p-block, such as $\mathrm{Zn}_{2} \mathrm{GeO}_{4}, \mathrm{ZnGa}_{2} \mathrm{O}_{4}$, and $\mathrm{Sr}_{2} \mathrm{Sb}_{2} \mathrm{O}_{7}$, are considered to be new semiconductor photocatalysts which can catalyze the oxidation of organic pollutants $[16,17]$. In addition to having higher pollutant degradation ability, these catalysts are also extremely stable and they are not inactive in the long process of photocatalytic reaction [16]. And these p-block semiconductor metal oxides have high catalytic performance, due to their special electronic structure [16-18]. However, the research of p-block metal oxide semiconductor photocatalyst is very limited, and most of the photocatalysts are only responsive to ultraviolet light. Therefore, to develop smaller size, large specific surface area, and accessible visible catalyst is a very effective method to promoting the photocatalytic degradation of organic pollutants.

In this paper, we reported that $\mathrm{ZnGa}_{2} \mathrm{~S}_{4}$ photocatalysts with nanostructure were prepared via a simple method 
of thiourea reactions and investigated the catalyst for visible-light photocatalytic degradation of organic pollutants. Thiourea reduction method is suitable for synthesizing a large amount of materials, and the synthetic materials are uniform nanocrystalline particles with high surface area. The prepared $\mathrm{ZnGa}_{2} \mathrm{~S}_{4}$ photocatalyst exhibits good photocatalytic activity and stability for methylene blue degradation.

\section{Experimental Section}

2.1. $\mathrm{ZnGa}_{2} \mathrm{O}_{4}$ Precursors Preparation. The $\mathrm{ZnGa}_{2} \mathrm{O}_{4}$ precursor was synthesized by coprecipitation method. A typical experimental procedure was as follows: $0.001 \mathrm{~mol}$ $\mathrm{Zn}\left(\mathrm{NO}_{3}\right)_{2} \cdot 6 \mathrm{H}_{2} \mathrm{O}$ (AR, Beijing Chemical Reagent Factory) and $0.002 \mathrm{~mol} \mathrm{Ga}\left(\mathrm{NO}_{3}\right)_{3} \cdot \mathrm{xH}_{2} \mathrm{O}$ (AR, Sigma Company) were mixed in $10 \mathrm{~mL}$ distilled water. Under vigorous stirring, the $\mathrm{pH}$ value of mixed solution was adjusted to 9.0 with ammonia solution. The obtained suspension was thoroughly stirred for $24 \mathrm{~h}$ at a temperature of $80^{\circ} \mathrm{C}$. The precipitation was obtained, then washed with distilled water and anhydrous ethanol (AR, Beijing Chemical Reagent Factory), and dried in air. The obtained products were annealed at $600^{\circ} \mathrm{C}$ for $5 \mathrm{~h}$ in air.

2.2. $\mathrm{ZnGa}_{2} \mathrm{~S}_{4}$ Photocatalyst Preparation. $0.1 \mathrm{~g} \mathrm{ZnGa}_{2} \mathrm{O}_{4}$ precursors were put in the quartz boat, and the quartz boat was put in the middle of quartz tube. Another quartz boat containing $1 \mathrm{~g}$ thiourea powders (AR, Beijing Chemical Reagent Factory) was put in the upper part of the airflow in the quartz boat, and it was made sure that the temperature at this place was stabilized at $250-350^{\circ} \mathrm{C}$ where thiourea could be decomposed at this temperature. The tube was evacuated by vacuum pump then filled with high-purity nitrogen in order to ensure the quartz tube without oxygen in the reaction. Heating tube furnace at the rate of $25^{\circ} \mathrm{C} / \mathrm{min}$, until the center position was about $700-800^{\circ} \mathrm{C}$ and kept at this temperature for 30 minutes. After the reaction, the $\mathrm{ZnGa}_{2} \mathrm{~S}_{4}$ powders were cooled naturally down to the room temperature and collected for test.

2.3. Photocatalytic Activity Experiment. Methylene blue (AR, Beijing Chemical Reagent Factory) was selected as pollutant to investigate the photocatalytic activity of the $\mathrm{ZnGa}_{2} \mathrm{~S}_{4}$. $300 \mathrm{~W}$ high pressure mercury lamp was selected as a light source, and all experiments were carried out in air. In a typical procedure, $0.1 \mathrm{~g} / \mathrm{L} \mathrm{MB}$ and a certain quantity of $\mathrm{ZnGa}_{2} \mathrm{~S}_{4}$ powder were stirred in $100 \mathrm{~mL}$ solution under visible light. Under certain time interval, $5 \mathrm{~mL}$ solution was taken out and centrifuged and then analyzed by UV-Vis spectrophotometer. $\mathrm{MB}$ decoloration efficiency by $\mathrm{ZnGa}_{2} \mathrm{~S}_{4}$ photocatalyst was calculated by the following formula:

$$
\operatorname{MB}(\%)=100 \% * \frac{\left(C_{0}-C_{t}\right)}{C_{0}},
$$

where $C_{0}$ and $C_{t}$ represented the concentration of $\mathrm{MB}(\mathrm{g} / \mathrm{L})$ at the initial time and the time $t$ in solution, respectively. In order to avoid the influence of $\mathrm{MB}$ absorption on catalytic reaction, the photocatalyst suspension was placed in the darkness for 30 minutes before using, to make the $\mathrm{MB}$ in $\mathrm{ZnGa}_{2} \mathrm{~S}_{4}$ photocatalyst reach adsorption-desorption equilibrium.
2.4. Characterization. The X-ray powder diffraction (XRD) patterns were carried out on a Rigaku Company D/Max 2200 $\mathrm{PC}$ using $\mathrm{Cu} \mathrm{K} \alpha$ radiation at $50 \mathrm{kV}$ and $50 \mathrm{~mA}$. Data were recorded at a scanning rate of $2^{\circ} / \mathrm{min}$ ranging from $10^{\circ}$ to $90^{\circ}$. UV-visible diffuse reflectance (UV-Vis) was measured by Beckman-DU-8B-type UV-Vis-NIR spectrophotometer; the scanning range was $200-800 \mathrm{~nm}$. The morphology of products was observed by $\mathrm{H}-9000$ field emission transmission electron microscope at accelerating voltage of $100-300 \mathrm{kV}$ (Hitachi). Energy-dispersive X-ray spectroscopy (EDX) was performed by the instrument attached on transmission electron microscope.

2.5. Computational Method. The electronic structures of $\mathrm{ZnGa}_{2} \mathrm{O}_{4}$ and $\mathrm{ZnGa}_{2} \mathrm{~S}_{4}$ were calculated by density functional theory (DFT). Exchange-correlation energy was calculated by generalized gradient approximation (GGA) which was functionalized by Perdew Burke-Ernzerhof (PBE) [19]. In the calculation, the cut-off energy we used was $500 \mathrm{eV}$; Monkhorst-Pack grid-5 $\times 5 \times 1$ was used for Brillouin zone integrations [20]. Geometric structure was fully relaxed until the Hellmann-Feynman force of each atom was less than $0.02 \mathrm{eV} / \AA$. We have implemented these algorithms within a powerful package called VASP [21, 22].

\section{Results and Discussion}

3.1. Transmission Electron Microscopy (TEM). Nanostructured $\mathrm{ZnGa}_{2} \mathrm{~S}_{4}$ photocatalyst is obtained at $800^{\circ} \mathrm{C}$ without adding catalyst. Instead of using traditional high toxicity catalyst $\mathrm{H}_{2} \mathrm{~S}$ and explosive gas $\mathrm{H}_{2}$, we use the thiourea as sulfur source, and $\mathrm{ZnGa}_{2} \mathrm{O}_{4}$ serves as precursor. Figures 1(a) and $1(\mathrm{~b})$ show the morphology of nanostructured $\mathrm{ZnGa}_{2} \mathrm{~S}_{4}$ photocatalyst. The synthesized size of $\mathrm{ZnGa}_{2} \mathrm{~S}_{4}$ nanocrystals is very small and uniform and their diameters are about 3$5 \mathrm{~nm}$. Layer space is approximately $3.03 \mathrm{~nm}$, corresponding to the (112) plane of $\mathrm{ZnGa}_{2} \mathrm{~S}_{4}$. The chemical elements of $\mathrm{ZnGa}_{2} \mathrm{O}_{4}$ precursors and $\mathrm{ZnGa}_{2} \mathrm{~S}_{4}$ photocatalyst were analyzed by EDX. As shown in Figures $1(\mathrm{c})$ and $1(\mathrm{~d})$, there are three kinds of elements $\mathrm{Zn}, \mathrm{Ga}$, and $\mathrm{O}$ in $\mathrm{ZnGa}_{2} \mathrm{O}_{4}$ precursors, whereas $\mathrm{ZnGa}_{2} \mathrm{~S}_{4}$ contains only $\mathrm{Zn}, \mathrm{Ga}$, and $\mathrm{S}$.

3.2. The Powder X-Ray Diffraction (XRD). The XRD patterns of $\mathrm{ZnGa}_{2} \mathrm{O}_{4}$ precursors and $\mathrm{ZnGa}_{2} \mathrm{~S}_{4}$ photocatalyst are shown in Figure 2, in which all the diffraction peaks $30.3^{\circ}$, $35.7^{\circ}, 43.4^{\circ}, 53.8^{\circ}, 57.4^{\circ}, 63.0^{\circ}$, and $74.6^{\circ}$, corresponding to $\mathrm{ZnGa}_{2} \mathrm{O}_{4}$ precursors (220), (311), (400), (422), (511), and (533) planes, occurred (JCPDS number 38-1240). For Figure 2(b), all the peaks $18.7^{\circ}, 29.3^{\circ}, 39.0^{\circ}, 49.1^{\circ}, 58.0^{\circ}$, and $79.5^{\circ}$, corresponding to the $\mathrm{ZnGa}_{2} \mathrm{~S}_{4}$ photocatalyst (001), (112), (121), (024), (132), and (136) planes (JCPDS number 40-1462), can be seen. As we can see, there is no other phase peak existing in the XRD patterns of two materials, indicating that the two materials are pure. After thiourea reaction, $\mathrm{ZnGa}_{2} \mathrm{O}_{4}$ precursors have been completely transformed into $\mathrm{ZnGa}_{2} \mathrm{~S}_{4}$ nanocrystals.

3.3. UV-Visible Diffuse Reflectance ( $U V$-Vis). Figure 3 displays $\mathrm{UV}-\mathrm{Vis}$ diffuse reflectance spectra of $\mathrm{ZnGa}_{2} \mathrm{O}_{4}$ precursors 


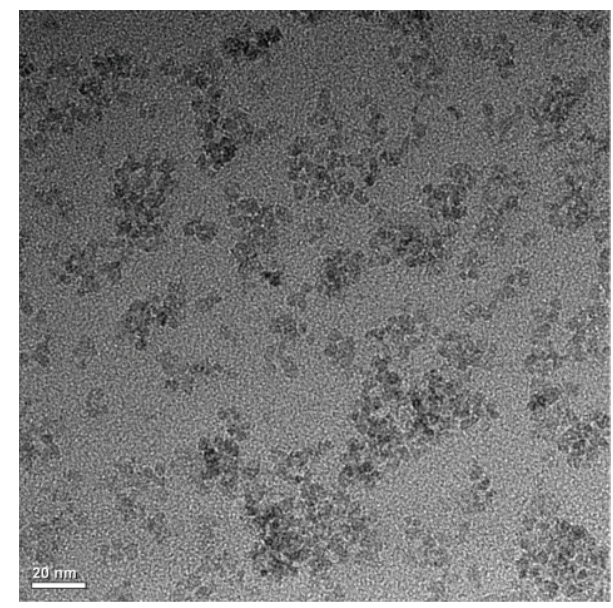

(a)

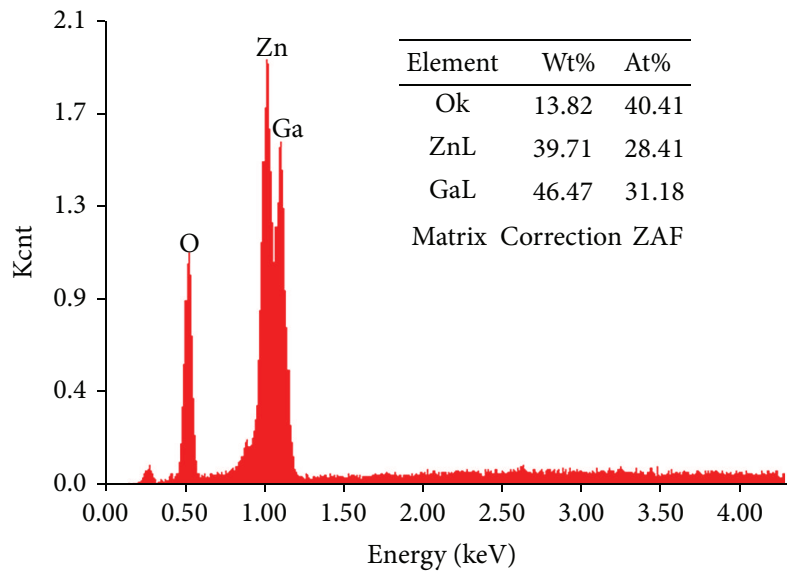

(c)

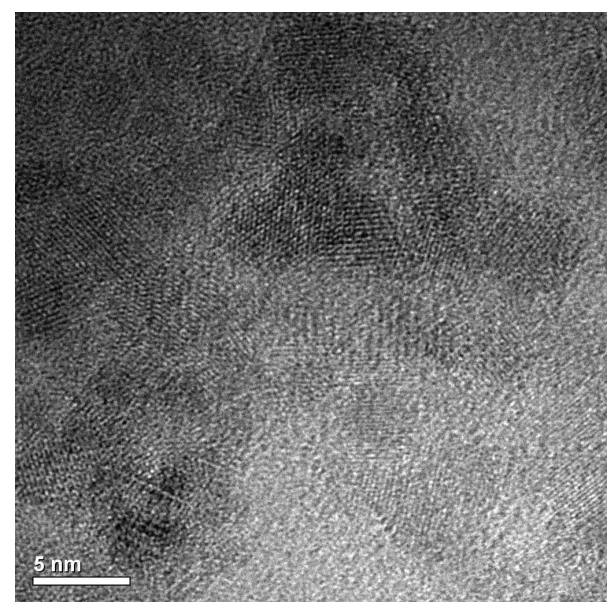

(b)

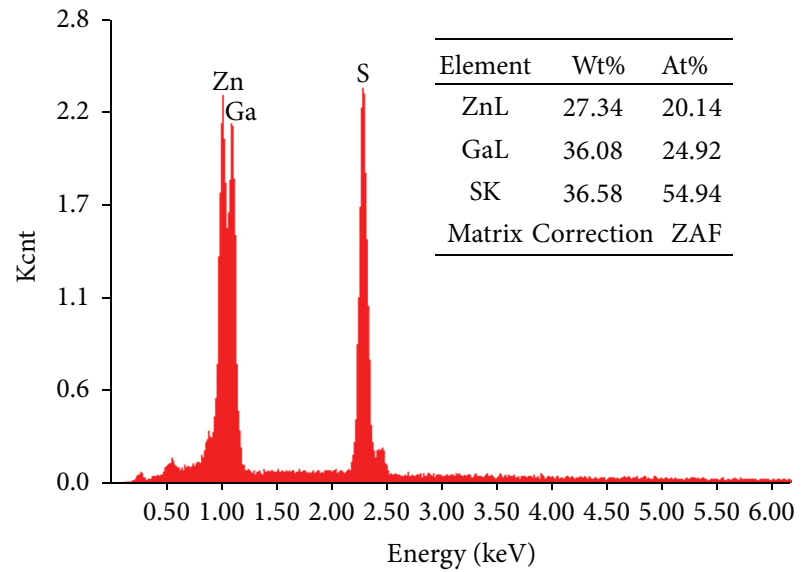

(d)

FIGURE 1: (a) TEM of $\mathrm{ZnGa}_{2} \mathrm{~S}_{4}$ photocatalysts; (b) HRTEM of $\mathrm{ZnGa}_{2} \mathrm{~S}_{4}$ photocatalysts; (c) and (d) represent EDX of $\mathrm{ZnGa}_{2} \mathrm{O}_{4}$ precursors and $\mathrm{ZnGa}_{2} \mathrm{~S}_{4}$, respectively.

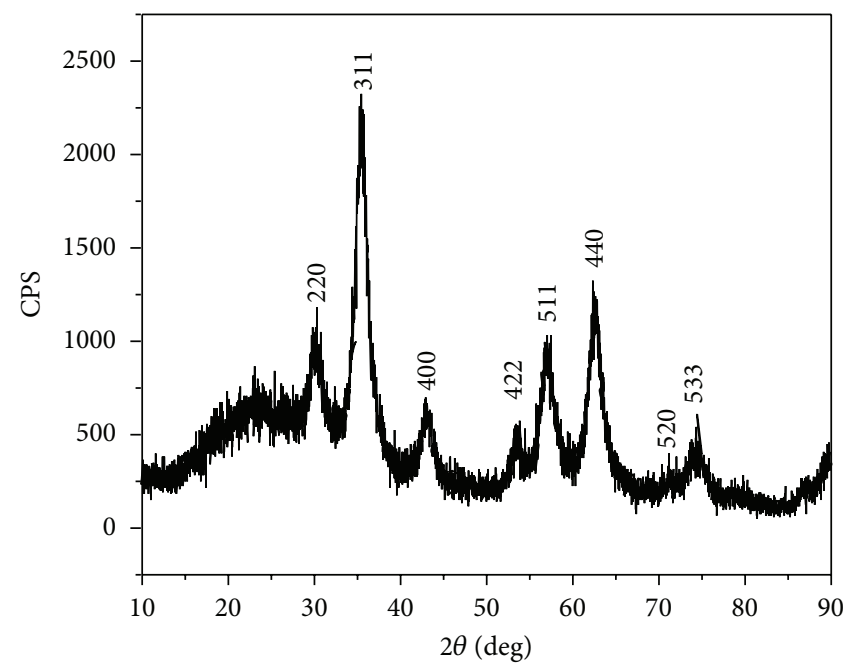

(a)

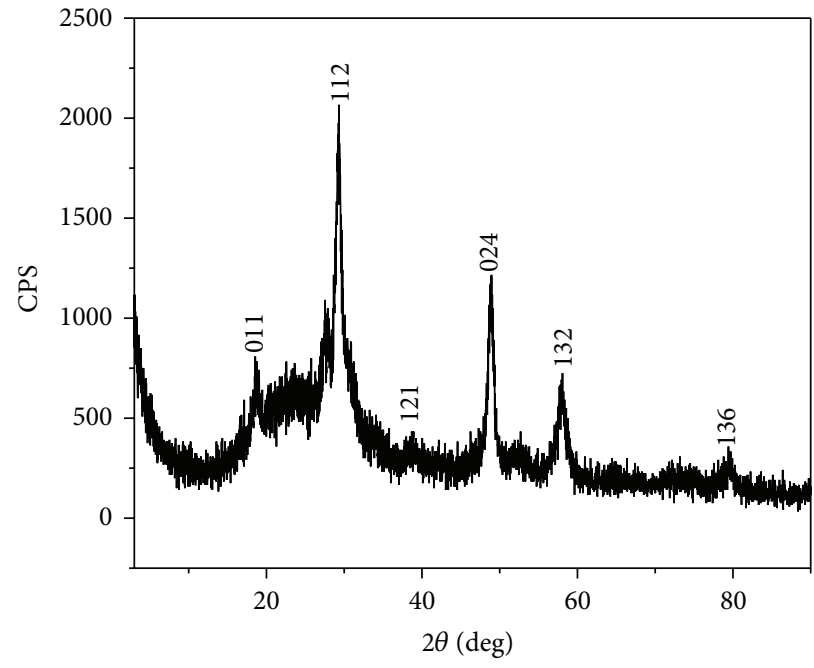

(b)

FIGURE 2: $\mathrm{XRD}$ of $\mathrm{ZnGa}_{2} \mathrm{O}_{4}$ precursors (a) and $\mathrm{ZnGa}_{2} \mathrm{~S}_{4}$ photocatalysts (b). 


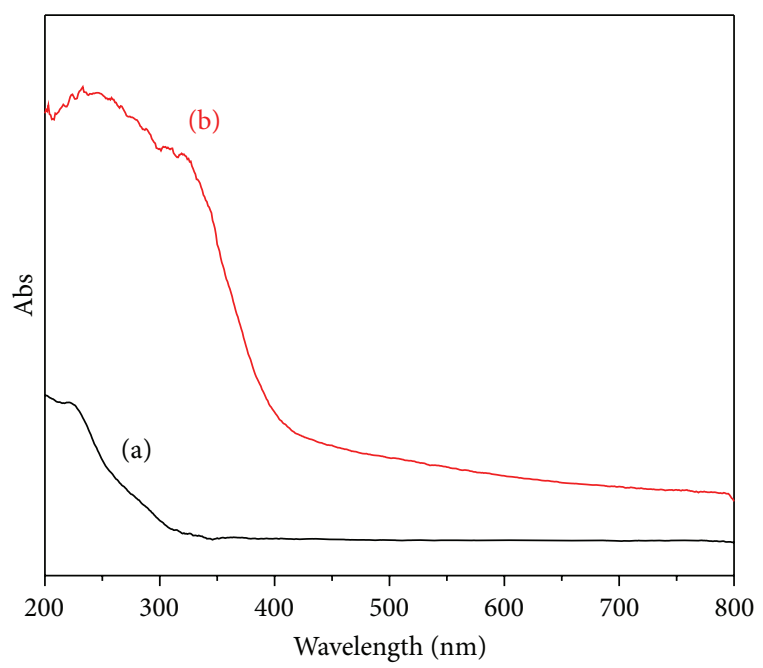

FIGURE 3: UV-Vis diffuse reflectance spectra of $\mathrm{ZnGa}_{2} \mathrm{O}_{4}$ precursors (a) and $\mathrm{ZnGa}_{2} \mathrm{~S}_{4}$ photocatalysts (b).

and $\mathrm{ZnGa}_{2} \mathrm{~S}_{4}$ photocatalyst. For $\mathrm{ZnGa}_{2} \mathrm{O}_{4}$ precursors, the main peak is located between 200 and $300 \mathrm{~nm}$, corresponding to a wide band gap with approximately $4.7 \mathrm{eV}$, showing that $\mathrm{ZnGa}_{2} \mathrm{O}_{4}$ precursors have photocatalytic activity only in the ultraviolet region [16]. However, after thiourea reduction reaction, the peak position of $\mathrm{ZnGa}_{2} \mathrm{~S}_{4}$ photocatalyst extends to the visible area, and its band gap becomes narrow, which is beneficial to the absorption of visible light.

3.4. Visible-Light Degradation. To investigate the photocatalytic performance of nanostructured $\mathrm{ZnGa}_{2} \mathrm{~S}_{4}$ in visible light, $\mathrm{MB}$ was selected as an organic contaminant. Many studies have reported that the quantity of catalyst can significantly influence the degradation efficiency of photocatalyst $[1,23,24]$. Therefore, a series of comparative tests were carried out to explore the influence of catalyst quantity on $\mathrm{MB}$ decolorizing efficiency, by changing the $\mathrm{ZnGa}_{2} \mathrm{~S}_{4}$ quantity from 0.2 to $0.6 \mathrm{~g} / \mathrm{L}$. As shown in Figure 4 , with increasing the catalyst quantity from 0.2 to $0.6 \mathrm{~g} / \mathrm{L}$, decolorization efficiency is increased from $61.3 \%$ to $99.2 \%$ after 60 -minute irradiation under visible light. The catalytic results show that the $\mathrm{ZnGa}_{2} \mathrm{~S}_{4}$ nanocrystalline visible photocatalyst exhibits good photocatalytic properties.

3.5. Degradation Mechanism. The high catalytic performance of $\mathrm{ZnGa}_{2} \mathrm{~S}_{4}$ photocatalyst could be explained by band structure calculations. At atmospheric pressure, $\mathrm{ZnGa}_{2} \mathrm{~S}_{4}$ crystal is cubic spinel structure, which belongs to the space group $f d \overline{3} m$ number 227 (Figure 5(a)). Zn cations form a tetrahedron, and the $\mathrm{Ga}$ cations locate in $\mathrm{GaS}_{6}\left(\mathrm{GaO}_{6}\right)$ octahedron. For comparison, we discuss the $\mathrm{ZnGa}_{2} \mathrm{O}_{4}$ properties first. Optimized lattice constant of the $\mathrm{ZnGa}_{2} \mathrm{O}_{4}$ is $8.46 \AA$, which is consistent with other reports (8.44 and $8.41 \AA$ ) [25, 26]. Electronic structure calculations are calculated with GGAPBE; it suggests that $\mathrm{ZnGa}_{2} \mathrm{O}_{4}$ has an indirect band gap of $2.33 \mathrm{eV}$. Usually, the LDA and GGA underestimate the

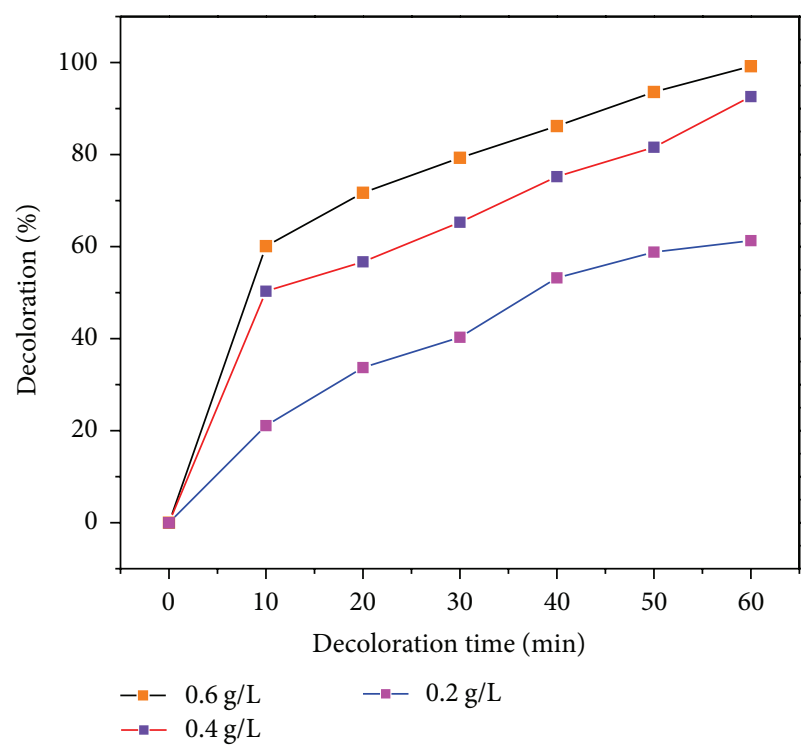

(a)

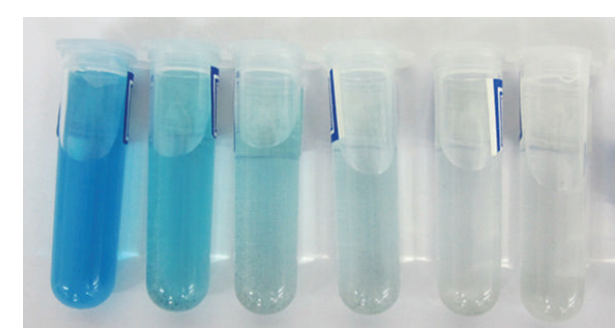

(b)

FIgURE 4: Decoloration of $\mathrm{MB}: \mathrm{ZnGa}_{2} \mathrm{~S}_{4}$ dosage $=0.2,0.4,0.6 \mathrm{~g} / \mathrm{L}$; initial $\mathrm{MB}$ concentration $=0.1 \mathrm{~g} / \mathrm{L}$ (inset photo is the decoloration process).

semiconductor band gap, so we adopt HSE06 hybrid functional calculations, which have been proved more accurately to predict the experimental results of energy gap [27]. The $\mathrm{ZnGa}_{2} \mathrm{O}_{4}$ band structure calculated by the HSE06 is shown in Figure 5(c). Compared with GGA-PBE calculations, we obtain the large band gap of $4.04 \mathrm{eV}$; the result is similar to the experimental band gap value $(4.4 \sim 5.0 \mathrm{eV})$ [28]. Previously, Sampath et al. reported that calculated $\mathrm{ZnGa}_{2} \mathrm{O}_{4}$ direct band gap was $2.79 \mathrm{eV}$ by the TB-LMTO; Lopez et al. found that the calculated indirect band gap was $2.78 \mathrm{eV}$ by the PAWLDA, and Karazhanovw and Ravindran's calculated indirect band gap was $3.09 \mathrm{eV}$ by the $\mathrm{LDA}+\mathrm{U}[29,30]$. Based on the GW and modified MBJ approximation, Dixit et al's obtained indirect band gaps were 4.57 and $4.71 \mathrm{eV}$, respectively [31]. It is found that our calculated results are consistent with the previously reported ones. Then, we also calculate the property of $\mathrm{ZnGa}_{2} \mathrm{~S}_{4}$; the calculation parameters are used the same as the $\mathrm{ZnGa}_{2} \mathrm{O}_{4}$. The study finds that $\mathrm{ZnGa}_{2} \mathrm{~S}_{4}$ also shows similar properties to indirect semiconductor $\mathrm{ZnGa}_{2} \mathrm{O}_{4}$. However, $\mathrm{ZnGa}_{2} \mathrm{~S}_{4}$ has a smaller band gap, which is calculated by GGA-PBE about $1.41 \mathrm{eV}$. Using HSE06, the calculated band gap value correction is $2.27 \mathrm{eV}$ (Figure 5(d)). Because the $\mathrm{ZnGa}_{2} \mathrm{~S}_{4}$ band gap becomes narrow after thiourea reduction, it can absorb visible light. Furthermore, under visible-light 


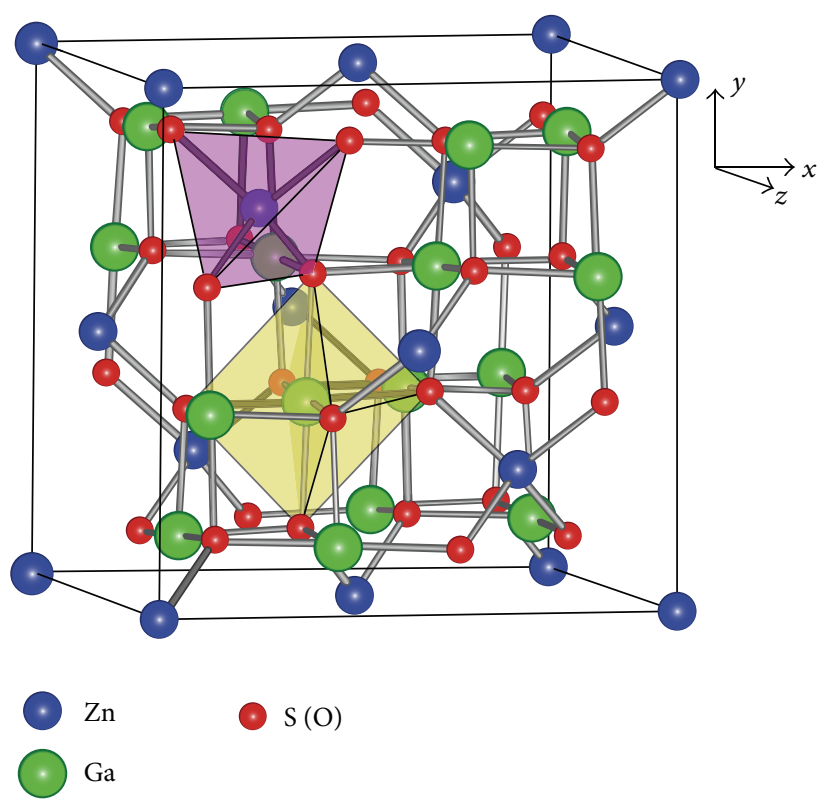

(a)

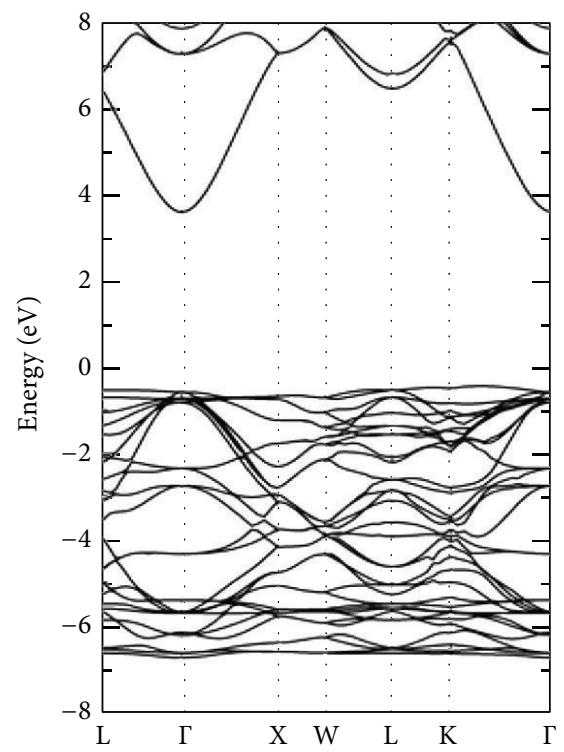

(c)

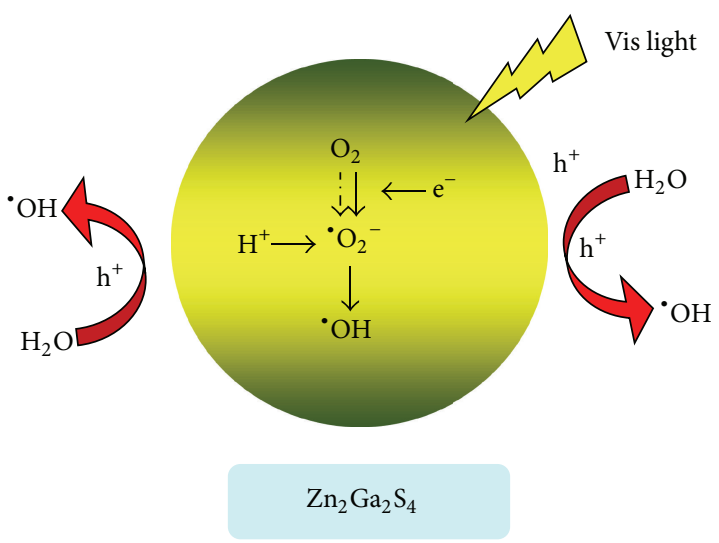

(b)

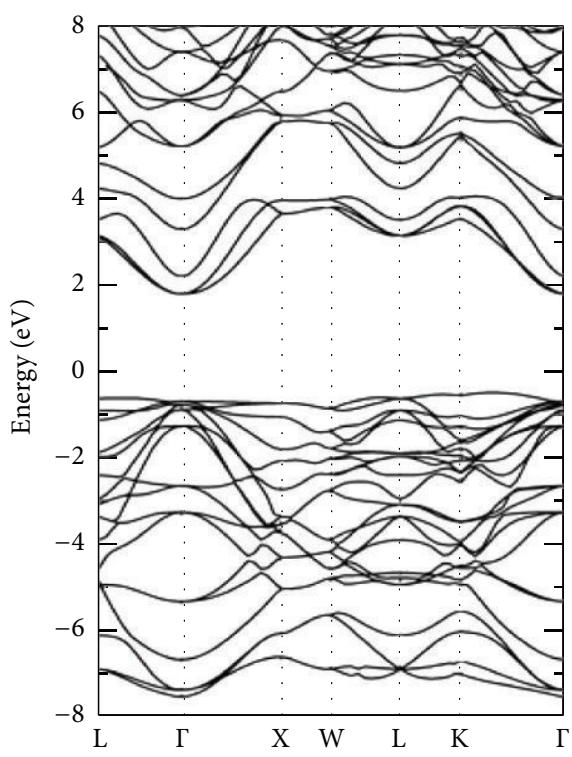

(d)

FIgURE 5: (a) Unit cell of the $\mathrm{ZnGa}_{2} \mathrm{~S}_{4}\left(\mathrm{ZnGa}_{2} \mathrm{O}_{4}\right)$ structure. The blue and green balls represent the $\mathrm{Zn}$ and Ga atoms, respectively, while the red ball corresponds to $\mathrm{S}$ or $\mathrm{O}$ atom. (b) The schematic diagram of the photocatalytic degradation of $\mathrm{MB}$ mechanism using $\mathrm{ZnGa}_{2} \mathrm{~S}_{4}$ photocatalysts. Band structures of (c) $\mathrm{ZnGa}_{2} \mathrm{O}_{4}$ and (d) $\mathrm{ZnGa}_{2} \mathrm{~S}_{4}$ calculated by the HSE06 functional. The Fermi level is set at zero.

irradiation, the electrons in the valence band of $\mathrm{ZnGa}_{2} \mathrm{~S}_{4}$ can be excited to the conduction band, thus leaving a large number of holes in the valence band. Some photoinduced electrons transfer to the surface of the $\mathrm{ZnGa}_{2} \mathrm{~S}_{4}$ and react with oxygen molecules, forming in ${ }^{\circ} \mathrm{O}_{2}{ }^{-}$. The remaining holes in the valence band are easier to react with adsorbed water molecules and produce ${ }^{\circ} \mathrm{OH}$ active radicals. Produced ${ }^{\circ} \mathrm{O}_{2}{ }^{-}$ can continue to combine with $\mathrm{H}^{+}$and form ${ }^{\circ} \mathrm{HO}_{2}$; they can capture the electrons and produce $\mathrm{H}_{2} \mathrm{O}_{2}$. The ${ }^{\circ} \mathrm{OH}$ radicals also can be produced when $\mathrm{H}_{2} \mathrm{O}_{2}$ molecules trap electrons.
All active groups, such as ${ }^{\bullet} \mathrm{OH},{ }^{\bullet} \mathrm{HO}_{2}$, and valence band holes, to a certain extent, can oxidize organic pollutants [31]. The MB photocatalytic degradation mechanism is shown in Figure 5(b).

\section{Conclusion}

The nanostructured $\mathrm{ZnGa}_{2} \mathrm{~S}_{4}$ with indirect band gap semiconductor was successfully synthesized via a simple thiourea reduction reaction. The obtained samples had small particle 
size and larger specific surface area. In the photocatalytic degradation of $\mathrm{MB}$, the material exhibited a significant stability and activity. Meanwhile, the photocatalytic degradation mechanism of $\mathrm{ZnGa}_{2} \mathrm{~S}_{4}$ on organic contamination was investigated. The $\mathrm{ZnGa}_{2} \mathrm{~S}_{4}$ photocatalyst with high catalytic activity and good stability can be applied to purification of water contamination.

\section{Conflict of Interests}

The authors declare that there is no conflict of interests regarding the publication of this paper.

\section{Acknowledgments}

This paper is supported by the Science and Technology Research Project Foundation of Jilin Province Education Department ([2013] 249), Natural Science Foundation of Changchun Normal University ([2010] 006), and National Natural Science Foundation of China (21041007).

\section{References}

[1] D. Mahanta, U. Manna, G. Madras, and S. Patil, "Multilayer self-assembly of $\mathrm{TiO}_{2}$ nanoparticles and polyaniline-graftedchitosan copolymer (CPANI) for photocatalysis," ACS Applied Materials \& Interfaces, vol. 3, no. 1, pp. 84-92, 2011.

[2] W. Chu, "Dye removal from textile dye wastewater using recycled alum sludge," Water Research, vol. 35, no. 13, pp. 3147-3152, 2001.

[3] T. Yan, X. Yan, R. Guo, W. Zhang, W. Li, and J. You, "Ag/AgBr/ BiOBr hollow hierarchical microspheres with enhanced activity and stability for $\mathrm{RhB}$ degradation under visible light irradiation," Catalysis Communications, vol. 42, pp. 30-34, 2013.

[4] X. Chen, J. Zhang, Y. Huo, and H. Li, "Preparation and visible light catalytic activity of three-dimensional ordered macroporous $\mathrm{CdS} / \mathrm{TiO}_{2}$ films," Chinese Journal of Catalysis, vol. 34, no. 5, pp. 949-955, 2013.

[5] L. Jiang, K. Li, L. Yan, Y. Dai, and Z. Huang, "Preparation of $\mathrm{Ag}(\mathrm{Au}) / \mathrm{Graphene}-\mathrm{TiO}_{2}$ composite photocatalysts and their catalytic performance under simulated sunlight irradiation," Chinese Journal of Catalysis, vol. 33, pp. 1974-1981, 2012.

[6] M. R. Hoffmann, S. T. Martin, W. Choi, and D. W. Bahnemann, "Environmental applications of semiconductor photocatalysis," Chemical Reviews, vol. 95, no. 1, pp. 69-96, 1995.

[7] B. Neppolian, H. C. Choi, S. Sakthivel, B. Arabindoo, and V. Murugesan, "Solar light induced and $\mathrm{TiO}_{2}$ assisted degradation of textile dye reactive blue 4," Chemosphere, vol. 46, no. 8 , pp. 1173-1181, 2002.

[8] X. Zhang, X. Lu, Y. Shen et al., "Three-dimensional $\mathrm{WO}_{3}$ nanostructures on carbon paper: photoelectrochemical property and visible light driven photocatalysis," Chemical Communications, vol. 47, no. 20, pp. 5804-5806, 2011.

[9] S. Zhao, M. Asuha, M. Zhang, and X. Wang, "Preparation and properties of $\mathrm{La}^{3+}$-doped $\mathrm{TiO}_{2}$ nanowires," Journal of Functional Materials, vol. 21, pp. 2577-2582, 2011.

[10] S.-T. Song, S.-X. Wu, Y.-S. Peng, X.-F. Zheng, and Q. Lian, "Preparation and photocatalytic properties of $\mathrm{TiO}_{2}$ microspheres," Journal of Functional Materials, vol. 43, no. 2, pp. 28812886, 2012.
[11] X. Chen, S. Shen, L. Guo, and S. S. Mao, "Semiconductorbased photocatalytic hydrogen generation," Chemical Reviews, vol. 110, no. 11, pp. 6503-6570, 2010.

[12] X. Chen, L. Liu, P. Y. Yu, and S. S. Mao, "Increasing solar absorption for photocatalysis with black hydrogenated titanium dioxide nanocrystals," Science, vol. 331, no. 6018, pp. 746-750, 2011.

[13] Z. Xiong and X. S. Zhao, "Nitrogen-doped titanate-anatase core-shell nanobelts with exposed $\{101\}$ anatase facets and enhanced visible light photocatalytic activity," Journal of the American Chemical Society, vol. 134, no. 13, pp. 5754-5757, 2012.

[14] B. Neppolian, S. Sakthivel, B. Arabindoo, M. Palanichamy, and V. Murugesan, "Solar/UV-induced photocatalytic degradation of three commercial textile dyes," Journal of Environmental Science and Health, vol. 34, pp. 1829-1838, 1999.

[15] J. S. Lee, K. H. You, and C. B. Park, "Highly photoactive, low bandgap $\mathrm{TiO}_{2}$ nanoparticles wrapped by graphene," Advanced Materials, vol. 24, no. 8, pp. 1084-1088, 2012.

[16] X. Chen, H. Xue, Z. Li, L. Wu, X. Wang, and X. Fu, “Ternary wide band Gap p-block metal semiconductor $\mathrm{ZnGa}_{2} \mathrm{O}_{4}$ for photocatalytic benzene degradation," The Journal of Physical Chemistry C, vol. 112, no. 51, pp. 20393-20397, 2008.

[17] H. Xue, Z. Li, L. Wu, Z. Ding, X. Wang, and X. Fu, "Nanocrystalline ternary wide band gap p-block metal semiconductor $\mathrm{Sr}_{2} \mathrm{Sb}_{2} \mathrm{O}_{7}$ : hydrothermal syntheses and photocatalytic benzene degradation," The Journal of Physical Chemistry C, vol. 112, no. 15, pp. 5850-5855, 2008.

[18] Z. Li, Z. Xie, Y. Zhang, L. Wu, X. Wang, and X. Fu, "Wide band gap p-block metal oxyhydroxide InOOH: A new durable photocatalyst for benzene degradation," Journal of Physical Chemistry C, vol. 111, no. 49, pp. 18348-18352, 2007.

[19] J. P. Perdew, K. Burke, and M. Ernzerhof, "Generalized gradient approximation made simple," Physical Review Letters, vol. 77, no. 18 , pp. 3865-3868, 1996.

[20] H. J. Monkhorst and J. D. Pack, "Special points for Brillouinzone integrations," Physical Review B: Solid State, vol. 13, no. 12, pp. 5188-5192, 1976.

[21] G. Kresse and J. Hafner, "Ab initio molecular dynamics for liquid metals," Physical Review B, vol. 47, no. 1, pp. 558-561, 1993.

[22] G. Kresse and J. Furthmüller, "Efficient iterative schemes for ab initio total-energy calculations using a plane-wave basis set," Physical Review B-Condensed Matter and Materials Physics, vol. 54, no. 16, pp. 11169-11186, 1996.

[23] S. Sakthivel, B. Neppolian, M. V. Shankar, B. Arabindoo, M. Palanichamy, and V. Murugesan, "Solar photocatalytic degradation of azo dye: comparison of photocatalytic efficiency of $\mathrm{ZnO}$ and $\mathrm{TiO}_{2}$," Solar Energy Materials \& Solar Cells, vol. 77, no. 1, pp. 65-82, 2003.

[24] S. Yang, Q. Yue, F. Wu et al., "Synthesis of the nanostructured $\mathrm{Cd}_{4} \mathrm{GeS}_{6}$ photocatalysts and their visible-light-driven photocatalytic degradation property," Journal of Alloys and Compounds, vol. 597, pp. 91-94, 2014.

[25] M. G. Brik, "First-principles calculations of electronic, optical and elastic properties of $\mathrm{ZnAl}_{2} \mathrm{~S}_{4}$ and $\mathrm{ZnGa}_{2} \mathrm{O}_{4}$," Journal of Physics and Chemistry of Solids, vol. 71, no. 10, pp. 1435-1442, 2010.

[26] A. Bouhemadou and R. Khenata, "Pseudo-potential calculations of structural and elastic properties of spinel oxides $\mathrm{ZnX}_{2} \mathrm{O}_{4}(\mathrm{X}=\mathrm{Al}, \mathrm{Ga}, \mathrm{In})$ under pressure effect," Physics Letters $A$, vol. 360, no. 2, pp. 339-343, 2006. 
[27] J. Heyd, G. E. Scuseria, and M. Ernzerhof, "Hybrid functionals based on a screened Coulomb potential," The Journal of Chemical Physics, vol. 118, no. 18, pp. 8207-8215, 2003.

[28] S. K. Sampath and J. F. Cordaro, "Optical properties of zinc aluminate, zinc gallate, and zinc aluminogallate spinels," Journal of the American Ceramic Society, vol. 81, no. 3, pp. 649-654, 1998.

[29] S. K. Sampath, D. G. Kanhere, and R. Pandey, "Electronic structure of spinel oxides: zinc aluminate and zinc gallate," Journal of Physics Condensed Matter, vol. 11, no. 18, pp. 3635-3644, 1999.

[30] S. Z. Karazhanovw and P. Ravindran, "Ab initio study of double oxides $\mathrm{ZnX}_{2} \mathrm{O}_{4}(\mathrm{X}=\mathrm{Al}, \mathrm{Ga}$, In) having spinel structure," Journal of the American Ceramic Society, vol. 93, no. 10, pp. 3335-3341, 2010.

[31] H. Dixit, N. Tandon, S. Cottenier et al., "Electronic structure and band gap of zinc spinel oxides beyond LDA: $\mathrm{ZnAl}_{2} \mathrm{O}_{4}$, $\mathrm{ZnGa}_{2} \mathrm{O}_{4}$ and $\mathrm{ZnIn}_{2} \mathrm{O}_{4}$," New Journal of Physics, vol. 13, Article ID 063002, 2011. 

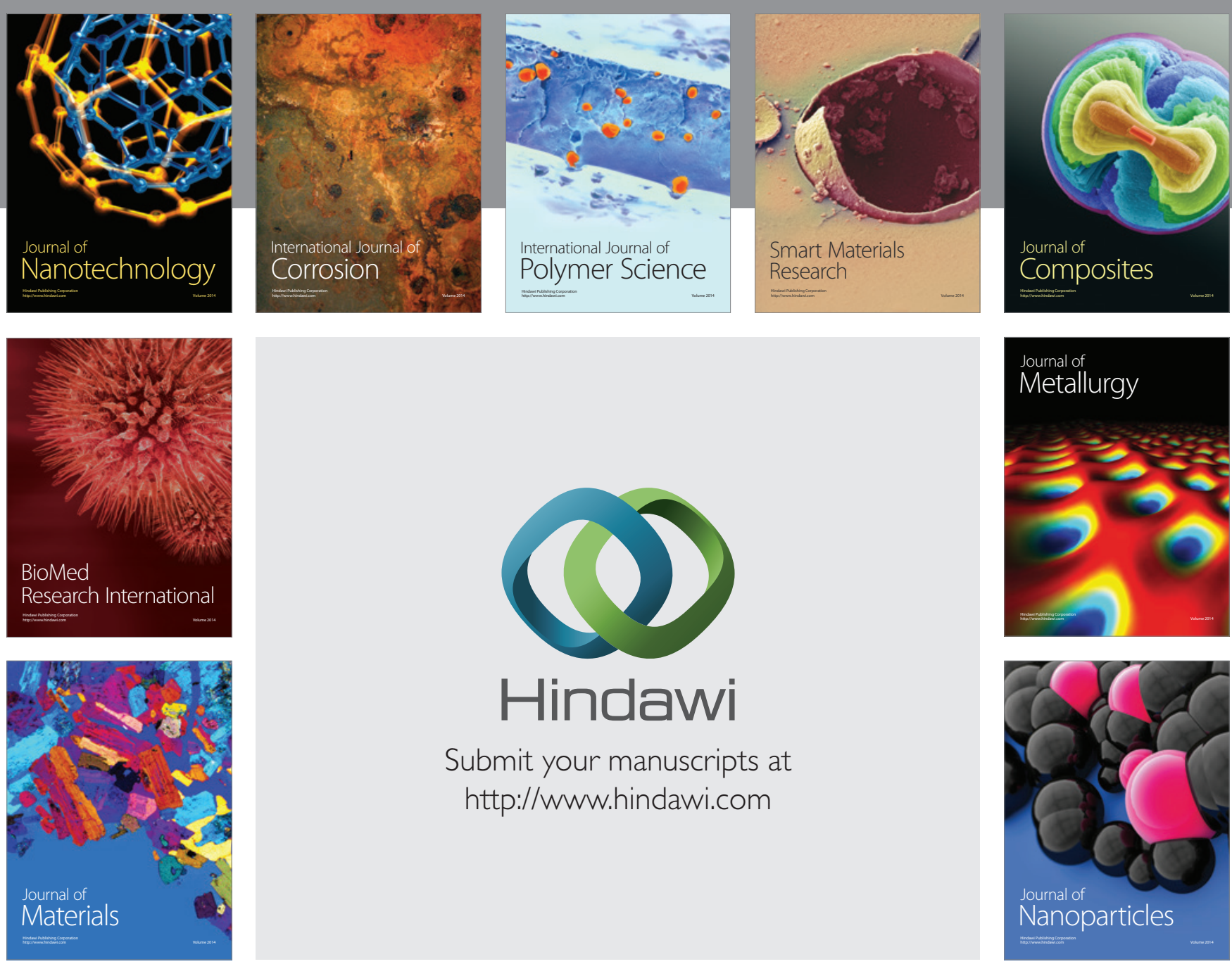

Submit your manuscripts at http://www.hindawi.com
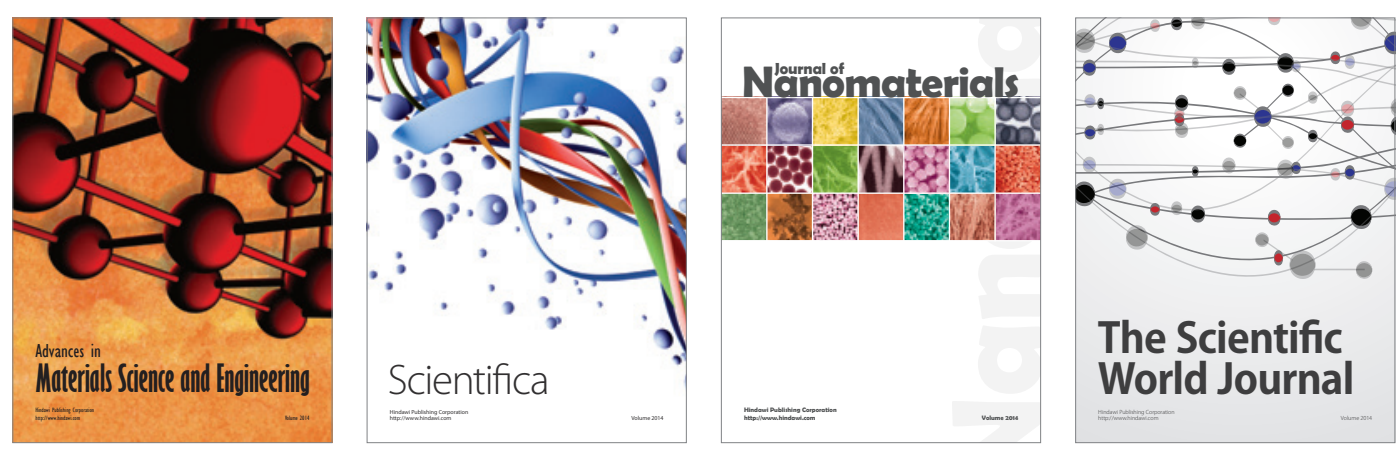

\section{The Scientific World Journal}
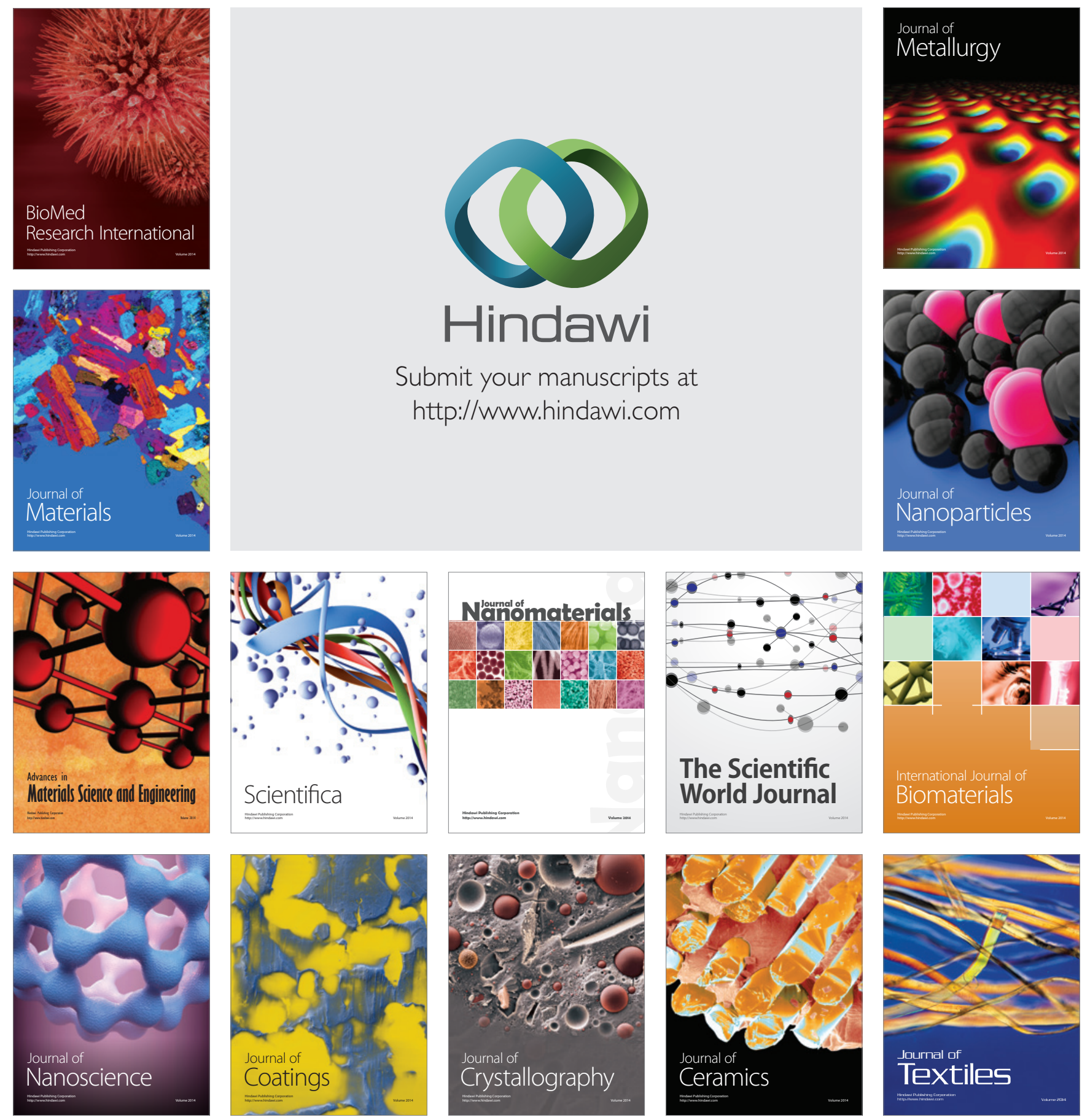